\title{
Expression and significance of androgen receptor coactivators in urothelial carcinoma of the bladder
}

\author{
Stephen A Booriian, Hannelore V Heemers, Igor Frank, Sara A Farmer ${ }^{1}$, \\ Lucy J Schmidt, Thomas J Sebo ${ }^{2}$ and Donald J Tindall
}

Department of Urology, Mayo Clinic, Guggenheim 1742, 200 First Street SW, Rochester, Minnesota 55905, USA

${ }^{1}$ Department of Health Sciences Research, Mayo Clinic, 200 First Street SW, Rochester, Minnesota 55905, USA

${ }^{2}$ Department of Laboratory Medicine and Pathology, Mayo Clinic, 200 First Street SW, Rochester, Minnesota 55905, USA

(Correspondence should be addressed to D J Tindall; Email: tindall.donald@mayo.edu)

\begin{abstract}
Urothelial carcinoma (UC) of the bladder is approximately three times more common in men than women. While the etiology for this gender difference in incidence remains unknown, a role for androgen receptor (AR) signaling has been suggested. The mechanisms by which AR activity is regulated in UC cells, however, are largely elusive. Here, we explore the significance of coregulators that are critical for the formation of a functional AR transcriptional complex, in UC cells. Using two AR-positive UC cell lines, TCC-SUP and UMUC3, we demonstrate the expression of the coactivators NCOA1, NCOA2, NCOA3, CREBBP, and EP300 in UC cells. small interfering RNA-mediated knockdown of the AR or any of these coactivators markedly impacted cell viability and abrogated androgen-dependent cell proliferation. Noteworthy, contrary to AR-positive prostate cancer cells, expression of these AR-associated coactivators was not androgen regulated in UC cells. To assess the clinical relevance of coactivator expression, we performed immunohistochemistry on paraffinembedded sections from 55 patients with UC of the bladder. We found that while 24 out of $55(44 \%)$ of tumors expressed the AR, each of the coactivators was expressed by $85-100 \%$ of the bladder cancers. Moreover, we noted a significant downregulation of NCOA1 expression in tumors versus adjacent, non-tumor bladder urothelium, with a mean of $68 \%$ (range $0-100$ ) of tumor cells demonstrating NCOA1 staining versus a mean of $81 \%$ (range $0-90)$ of non-tumor cells $(P=0.03)$. Taken together, our data suggest an important role for AR-associated coactivators in UC and point toward differences in the regulation of AR activity between bladder and prostate cancer cells.
\end{abstract}

Endocrine-Related Cancer (2009) 16 123-137

\section{Introduction}

Urothelial carcinoma (UC) of the bladder is the fourth most common cancer among men in the US and is approximately three times more common in men than women (Jemal et al. 2007). The etiology for this difference in incidence by sex is unknown. Excessive exposure to cigarette smoke and industrial chemicals in males has been suggested as an explanation, although a previous study demonstrated that the gender-related risk of bladder cancer persisted even after controlling for these factors (Hartge et al. 1990).

Hormonal differences have also been suggested to play a role in the gender disparity incidence of bladder cancer. Indeed, animal studies have demonstrated that the incidence of spontaneous and chemically induced bladder tumor development is significantly greater in male than female rats (Okajima et al. 1975, Boorman 1977, Miyamoto et al. 2007). Moreover, treatment of male rats with androgen deprivation reduces the development of chemically induced bladder carcinomas (Okajima et al. 1975, Imada et al. 1997, Miyamoto et al. 2007).

To investigate the potential role of sex steroids in bladder cancer, the expression of hormone receptors in human bladder cancer specimens has been evaluated (Zhuang et al. 1997, Boorjian et al. 2004, Shen et al. 2006, Teng et al. 2008). In particular, the androgen receptor (AR) has been detected in normal bladder epithelium and in bladder cancers from men and women (Zhuang et al. 1997, Boorjian et al. 2004). 
Several studies using AR antagonists, small interfering RNA (siRNA) against the AR, and androgen deprivation have furthermore provided evidence of a functional AR signaling pathway in bladder cancer, and have demonstrated an important role for the AR in UC cell proliferation (Chen et al. 2003, Miyamoto et al. 2007). Nevertheless, to our knowledge, the mechanisms that regulate the activity of the AR in bladder cancer cells have not been reported.

The bladder is embryologically derived primarily from the urogenital sinus, which in males also gives rise to the prostate (Moore \& Persaud 1993). Thus, the potential exists for similar mechanisms of AR regulation in the bladder and prostate. Recent studies have refined our understanding of the mechanisms of AR action in androgen-dependent and androgenrefractory prostate cancer (Debes \& Tindall 2004, Dehm \& Tindall 2006). A common theme among the mechanisms that have been proposed to explain AR action in prostate cancer cells is the involvement of coactivator proteins. Coactivators are recruited by the AR upon DNA binding and subsequently function to enhance AR-dependent transcription by facilitating DNA occupancy, chromatin remodeling, and recruitment of transcription factors, as well as by ensuring appropriate folding of the AR, AR protein stability, and/or proper AR subcellular distribution (Debes \& Tindall 2004, Heinlein \& Chang 2004, Lonard \& O’Malley 2005, Heemers \& Tindall 2007). Moreover, aberrant AR activity in prostate cancer cells has been shown to depend at least in part on deregulated expression of several coactivator proteins (Debes et al. 2003, Agoulnik et al. 2005, 2006, Zhou et al. 2005).

The expression and functional significance of AR coactivators in the bladder have not, however, been well defined. Here, we investigated the expression and relevance of AR coactivators in human UC cells lines and patient tissue specimens.

\section{Materials and methods}

\section{Cell culture}

The human UC cell lines TCC-SUP and UMUC3 were purchased from American Type Culture Collection (Manassas, VA, USA). TCC-SUP was derived from an invasive bladder tumor in a female patient, while the UMUC3 cell line was derived from a UC tumor in a male patient. Cells were cultured in phenol red-free DMEM (Invitrogen) supplemented with 9\% fetal bovine serum (FBS; Biosource, Rockville, MD, USA), 100 units $/ \mathrm{ml}$ streptomycin, and $0.25 \mu \mathrm{g} / \mathrm{ml}$ amphotericin B (Invitrogen). All cultures were maintained in a humidified incubator at $37{ }^{\circ} \mathrm{C}$ in $5 \%$ $\mathrm{CO}_{2}$. In experiments designed to assess the effects of androgen treatment, cells were seeded in medium containing 9\% charcoal-stripped serum (CSS), 100 units $/ \mathrm{ml}$ streptomycin, and $0.25 \mu \mathrm{g} / \mathrm{ml}$ amphotericin B. For siRNA transfection studies, antibiotics were left out of the culture medium.

\section{Reagents}

Methyltrienolone (R1881) was purchased from DuPont (Boston, MA, USA), and staurosporine was obtained from Sigma. Antibodies were purchased from different manufacturers: EP300 and CREBBP were obtained from Santa Cruz Biotechnology (Santa Cruz, CA, USA), and NCOA1, NCOA2, and NCOA3 were purchased from BD Transduction Laboratories (San Jose, CA, USA), while poly(ADP-ribose)polymerase (PARP) and $\beta$-actin were obtained from Cell Signaling (Beverly, MA, USA). The AR antibody utilized in western blot analysis was purchased from Upstate Cell Signaling Solutions (Lake Placid, NY, USA), and the AR antibody used for immunohistochemistry was obtained from Novocastra Lab (Newcastle, UK).

\section{Preparation of whole-cell lysates}

Cells were washed twice with ice-cold PBS, and whole-cell lysis buffer (110 mmol/l SDS, $100 \mathrm{mmol} / \mathrm{l}$ dithiothreitol, $80 \mathrm{mmol} / \mathrm{l}$ Tris- $\mathrm{HCl}$ ( $\mathrm{pH}$ 6.9), $10 \%$ glycerol) was pipetted onto the culture dish. The resulting cell lysates were then boiled for $5 \mathrm{~min}$ and stored at $-20{ }^{\circ} \mathrm{C}$ until analysis.

\section{Western blotting}

Equal amounts of protein were loaded onto NuPage 3-8\% Tris-acetate or 10\% Bis-Tris gels (Invitrogen), and electrophoresis was done according to the manufacturer's instructions. Proteins were blotted onto nitrocellulose membranes (Bio-Rad). Blots were reprobed with antibodies against $\beta$-actin to evaluate potential differences in protein loading.

\section{Cell viability assay}

TCC-SUP and UMUC3 cells were seeded in 96-well tissue culture plates at a density of $2 \times 10^{3}$ cells per well in their regular medium. At the indicated time points, cell viability was assessed by means of a Cell Titer 96 Aqueous One solution cell proliferation assay (Promega) according to the manufacturer's instructions. In experiments designed to assess the effects of androgen treatment, cells were seeded in medium containing 9\% CSS and were treated with $1 \mathrm{nM} \mathrm{R} 1881$ 
$48 \mathrm{~h}$ after seeding. For siRNA transfection studies, antibiotics were left out of the culture medium, and cells were transfected with siGenome SMART pools (Dharmacon, Lafayette, CO, USA) directed against the AR, AR coactivators, or a control SMART pool as described (Heemers et al. 2007). After 12-16 h, medium was changed, and cell viability was subsequently assessed at the indicated time points. Values from five wells were measured per treatment group for each time point.

\section{RNA interference}

TCC-SUP and UMUC3 cells were seeded at a density of $3 \times 10^{5}$ in $100 \mathrm{~mm}$ culture dishes in phenol red-free Dulbecco's modified Eagle's medium (DMEM) supplemented with 9\% FBS. The next day, cells were transfected with 500 pmol siGenome SMART pool directed against NCOA1, NCOA2, NCOA3, CREBBP, EP300, or AR; 500 pmol of a non-targeting control SMART pool (Dharmacon); or mock transfected using Lipofectamine 2000 reagent (Invitrogen) following the manufacturer's instructions.

\section{RNA isolation}

At the time of cell harvest, cells were washed with PBS and harvested in Trizol solution (Invitrogen). RNA was isolated according to the manufacturer's instructions.

\section{Real-time RT-PCR}

cDNA was prepared from $3 \mu \mathrm{g}$ total RNA using a SuperScriptIII first-strand synthesis system (Invitrogen), following the manufacturer's instructions. Real-time RT-PCR was performed using SYBR Green PCR mastermix (Applied Biosystems, Foster City, CA, USA) on an ABI Prism 7700 SDS instrument as described (Debes et al. 2005). The primers used are listed in Table 1. GAPDH control primers were purchased from Applied Biosystems.

Table 1 Primers used to perform real-time RT-PCR

\begin{tabular}{lcc}
\hline Target gene & Primer pair & Primer sequence \\
\hline NCOA1 & $5^{\prime}$ & CTCTGGATTCAGGGCTTCTG \\
& $3^{\prime}$ & GTTCGGCAGTTGTTGTCAAA \\
NCOA2 & $5^{\prime}$ & GGCAAGAAGAGTTCCCATGA \\
NCOA3 & $3^{\prime}$ & CTGCTCTCATGGTGCTGGTA \\
& $5^{\prime}$ & CACATGGGAGTCCTGGTCTT \\
CREBBP & $3^{\prime}$ & GGTTCCCAGTATTGCCAGAA \\
& $5^{\prime}$ & CCCCTGGGAATAATCCAAT \\
EP300 & $3^{\prime}$ & CGTTCATCAGTGGGTTTGTG \\
& $5^{\prime}$ & CAAACGCCGAGTCTTCTTTC \\
& $3^{\prime}$ & GTTGAGCTGCTGTTGGCATA \\
\hline
\end{tabular}

\section{Study population for UC tissue analysis}

Upon approval from our Institutional Review Board, 60 patients treated with radical cystectomy for UC of the bladder between 1990 and 1994 were identified from a review of the Mayo Clinic Cystectomy Registry. Twenty patients each with pathological stage $\mathrm{T} 1, \mathrm{~T} 2$, and $\mathrm{T} 3 / 4$ tumors were randomly selected in order to evaluate the distribution of $A R$ and $A R$ coactivator expression across various tumor stages.

\section{Immunohistochemical staining}

Formalin-fixed, paraffin-embedded tissues were cut into $5 \mu \mathrm{m}$ sections, deparaffinized, and rehydrated in a graded series of ethanols. Antigen retrieval was performed by heating tissue sections in $1 \mathrm{mM}$ EDTA (pH 8) to $121{ }^{\circ} \mathrm{C}$ using a Digital Decloaking Chamber (Biocare Medical, Walnut Creek, CA, USA), cooling to $90{ }^{\circ} \mathrm{C}$, and incubating for $5 \mathrm{~min}$. Sections were washed in wash buffer (Dako, Carpenteria, CA, USA) before being placed onto the Autostainer Plus (Dako). Sections were then blocked for endogenous peroxidase for 5 min using endogenous blocking solution (Dako), washed twice, and incubated for $5 \mathrm{~min}$ in serum-free protein block (Dako). This was followed by incubation for $60 \mathrm{~min}$ at room temperature (overnight at $4{ }^{\circ} \mathrm{C}$ for NCOA1) in mouse monoclonal anti-human NCOA1 antibody diluted 1:50 with DaVinci Green antibody diluent (Biocare Medical), mouse monoclonal antihuman NCOA2 antibody diluted 1:200, mouse monoclonal anti-human NCOA3 antibody diluted 1:100, rabbit polyclonal anti-EP300 antibody diluted 1:200, rabbit polyclonal anti-CREBBP antibody diluted 1:500, or mouse monoclonal anti-human AR antibody diluted 1:100. Secondary antibody staining for the NCOA1, NCOA3, and the AR was achieved by incubating sections in probe from the Mouse HRPPolymer Kit (Biocare Medical), washing, and incubating with polymer from the Mouse HRP-Polymer Kit. Secondary antibody staining to NCOA2, EP300, and CREBBP was achieved by incubating sections with the EnVision + Dual Link System-HRP (Dako) for $15 \mathrm{~min}$. All sections were visualized by incubating in Betazoid DAB (Biocare Medical) for $5 \mathrm{~min}$, and were then counterstained with hematoxylin, dehydrated in ethanol, cleared in xylene, and coverslipped.

Negative control tumor sections were treated identically to all other sections except that the primary antibody was not included in the staining. Prostate tissue from archival specimens was used as a positive control for the AR and coactivators. The percentage of tumor and adjacent, non-tumor cells that stained positive for AR and AR coactivators was quantified 
in $5-10 \%$ increments. Expression was considered positive if there was histological evidence of staining in $5 \%$ or more of cells. Cases with less than $5 \%$ staining were considered negative. All quantitation was performed by a single urologic pathologist (T J Sebo).

\section{Statistical analysis}

Comparisons of mean absorbance values for cell viability assays were done using paired Student's $t$-test. Associations of immunohistochemical staining for the AR and coactivators with clinicopathological features were evaluated using Kruskal-Wallis, Wilcoxon rank sum, $\chi^{2}$, and Fisher's exact tests, as appropriate. McNemar's and Wilcoxon signed-rank tests were used to evaluate the differences in AR and coactivator expression between UC specimens and paired, adjacent non-cancerous bladder tissue. Statistical analyses were done using the SAS software package (SAS Institute, Cary, NC, USA). All tests were two-sided, and $P$ values $<0.05$ were considered statistically significant.

\section{Results}

\section{AR expression and androgen regulation in UC cell lines}

To confirm the expression of the AR in TCC-SUP and UMUC3 cells, AR was assessed by immunoblotting whole cell lysates from cultured cells. As shown in Fig. 1A, AR protein was detected in both cell lines, which is consistent with the previous reports (Miyamoto et al. 2007). A relatively higher level of AR expression was noted in TCC-SUP cells than in UMUC3 cells. Compared with the AR-positive prostate cancer cell line LNCaP, AR expression levels in TCC-SUP and UMUC3 cells were low (less than $10 \%$ of LNCaP levels, data not shown). To explore whether androgens affect AR expression, cells were

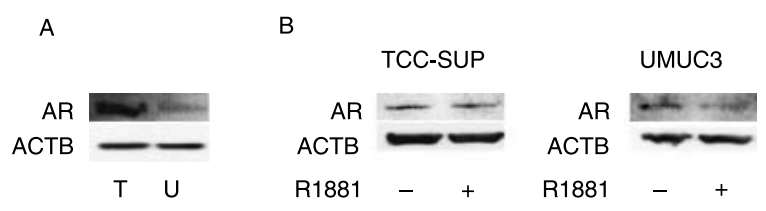

Figure 1 AR expression in UC cell lines. (A) Cell extracts from TCC-SUP $(T)$ and UMUC3 $(U)$ cells were subjected to immunoblotting using an antibody directed against the AR. (B) Cells were cultured in the presence or absence of the synthetic androgen R1881 (1 nM) for $48 \mathrm{~h}$. Western blot analysis was performed to assess AR expression. To evaluate potential intersample loading differences, blots were stripped and reprobed with an antibody recognizing $\beta$-actin (ACTB).

Blots representative of three separate experiments are shown. grown in medium supplemented with CSS in order to deplete androgens and treated with the synthetic androgen R1881 ( $1 \mathrm{nM})$ for $48 \mathrm{~h}$. Western blot analysis demonstrated no change in AR expression after androgen treatment in TCC-SUP cells but showed a moderate decrease in $\mathrm{AR}$ protein expression for the UMUC3 cell line (Fig. 1B). These results were confirmed in both cell lines at the mRNA level using real-time reverse transcription PCR (data not shown). Moreover, similar effects were seen when cells were treated with the natural androgen dihydrotestosterone (data not shown). Subsequent sequencing of the mRNA revealed a wild-type AR sequence in both cell lines, with some variability in the CAG repeat length (22 CAG repeats in TCC-SUP cells, 20 repeats in UMUC3 cells, data not shown). These observations are consistent with AR CAG polymorphisms that have been described in patients with UC (Liu et al. 2007).

Next, we assessed the androgen responsiveness of UC cells by investigating the effect of androgen treatment on cell proliferation. To this end, cells were seeded in medium supplemented with CSS and stimulated with R1881 (1 nM) or ethanol vehicle. Cell viability was evaluated at the indicated time points by determining metabolic activity by means of a 3-(4,5-dimethylthiazol2-yl)-5-(3-carboxymethoxyphenyl)-2-(4-sulfophenyl)$2 \mathrm{H}$ tetrazolium (MTS) assay. For both TCC-SUP and UMUC3, a slight increase in cell viability was first noted $24 \mathrm{~h}$ after androgen treatment and became increasingly pronounced over time (Fig. 2). These data indicate that these cell lines are indeed androgen responsive, and that androgen treatment is advantageous for cell proliferation. Moreover, while a statistically significant increase in the number of viable cells appeared earlier for TCC-SUP cells, the absolute increase in cell viability with androgen treatment appeared particularly evident for the UMUC3 cell line. Importantly, however, both cell lines demonstrated increased viability over time even in the absence of androgen treatment, in contrast to what has been noted for example in LNCaP prostate cancer cells (Veldscholte et al. 1994). These results indicate that, although bladder cancer cells are hormonally responsive, androgens may not be required for cell viability.

\section{AR coactivator expression in UC cell lines}

Despite evidence for a functional AR signaling pathway in UC cell lines (Figs 1 and 2, Chen et al. 2003, Miyamoto et al. 2007), the mechanisms by which AR activity is regulated in bladder cancer are largely unknown. Therefore, in view of the demonstrated importance of coactivators in AR-dependent transcription in the prostate (Heinlein \& Chang 2004, 

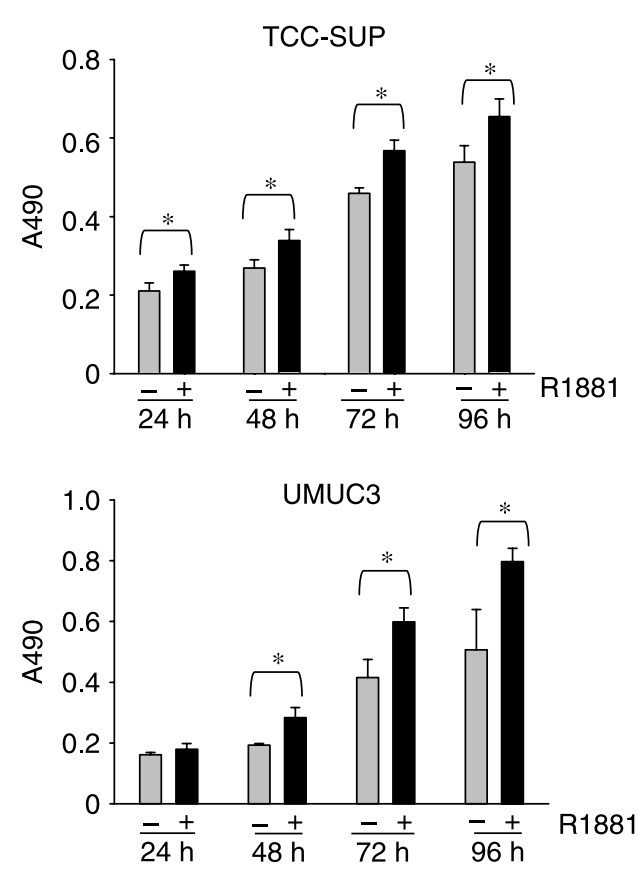

Figure 2 Androgen-stimulated cell viability in AR-positive UC cell lines. Cells were seeded in medium supplemented with CSS. Forty-eight hours later, medium was changed and cells were treated with $1 \mathrm{nM}$ R1881 (black columns) or ethanol vehicle (gray columns). Forty-eight and $96 \mathrm{~h}$ later, cell viability was assessed by means of an MTS assay reading absorbance at $490 \mathrm{~nm}$. Columns and vertical bars represent the mean \pm S.E.M. of five individual measurements. *Statistically significant difference compared with untreated cells, $P<0.05$.

Heemers \& Tindall 2007), and in steroid-dependent malignancies including prostate (Debes \& Tindall 2004, Heemers \& Tindall 2005) and breast (Bouras et al. 2001, Osborne et al. 2003) cancers, we investigated the expression of a set of coactivators in UC cells. For this, we chose the coactivators NCOA1, NCOA2, NCOA3, CREBBP, and EP300. These coregulators fulfill central roles in the generation and function of the AR transcriptional complex (Heemers $\&$ Tindall 2007). In addition, they have been reported to be overexpressed in prostate cancer, an effect that has been attributed in part to androgen-dependent expression (Comuzzi et al. 2004, Agoulnik et al. 2006, Heemers et al. 2007, Heemers unpublished observations). As shown in Fig. 3, all five coactivators are expressed by both TCC-SUP and UMUC3 cells.

\section{Functional significance of AR coactivators in UC cell lines}

In view of the central role of the AR and AR-associated coactivators in the proliferation of other AR-positive malignancies such as prostate cancer (Heemers \& Tindall 2007), we next evaluated the importance of these

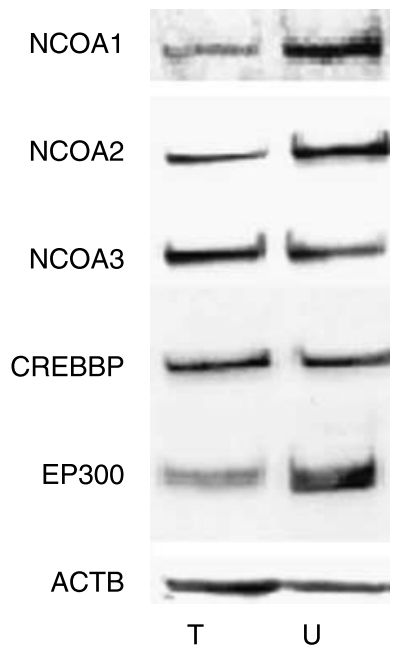

Figure 3 Expression of AR core coactivators in AR-positive UC cell lines. Whole-cell lysates from TCC-SUP (T) and UMUC3 (U) cells grown in their regular culture medium were subjected to western blotting using antibodies directed against NCOA1, NCOA2, NCOA3, CREBBP, and EP300. To assess potential intersample loading differences, blots were stripped and reprobed with an antibody recognizing $\beta$-actin (ACTB). Blots representative of three separate experiments are shown.

coactivators for proliferation in UC cells. To this end, we assessed the dependence of TCC-SUP and UMUC3 on AR and AR coactivator expression for cell viability.

Cells were transfected with siRNAs targeting the AR, AR coactivators, or non-targeting control siRNAs. At the indicated time points, cell viability was evaluated using an MTS assay. For TCC-SUP cells, we found that, although only minor or no effects on cell viability were observed $48 \mathrm{~h}$ after transfection, by $96 \mathrm{~h}$ downregulation of AR or AR coactivator expression was associated with a marked decrease in cell viability (Fig. 4, left). Likewise, in UMUC3 cells, loss of AR, NCOA2, NCOA3, or EP300 led to a decrease in cell viability with similar kinetics (Fig. 4, right). Interestingly, however, transfection with siRNAs targeting NCOA 1 and CREBBP resulted in an increase in the viability of UMUC3 cells that again was first noted at $48 \mathrm{~h}$ and became more pronounced over time.

Compensatory increases in the expression levels of functionally related coregulators upon loss of coactivators have been reported (Wang et al. 2005). To explore whether such alterations in coregulator expression levels could account for the increases in UMUC3 cell viability following siRNA-mediated silencing of NCOA1 and CREBBP, we explored the reciprocal effect of the knockout of any of the five coregulators on the expression level of the other four cofactors. As shown in Fig. 5, major differences in coregulator expression patterns could not be observed between the two UC cell lines 

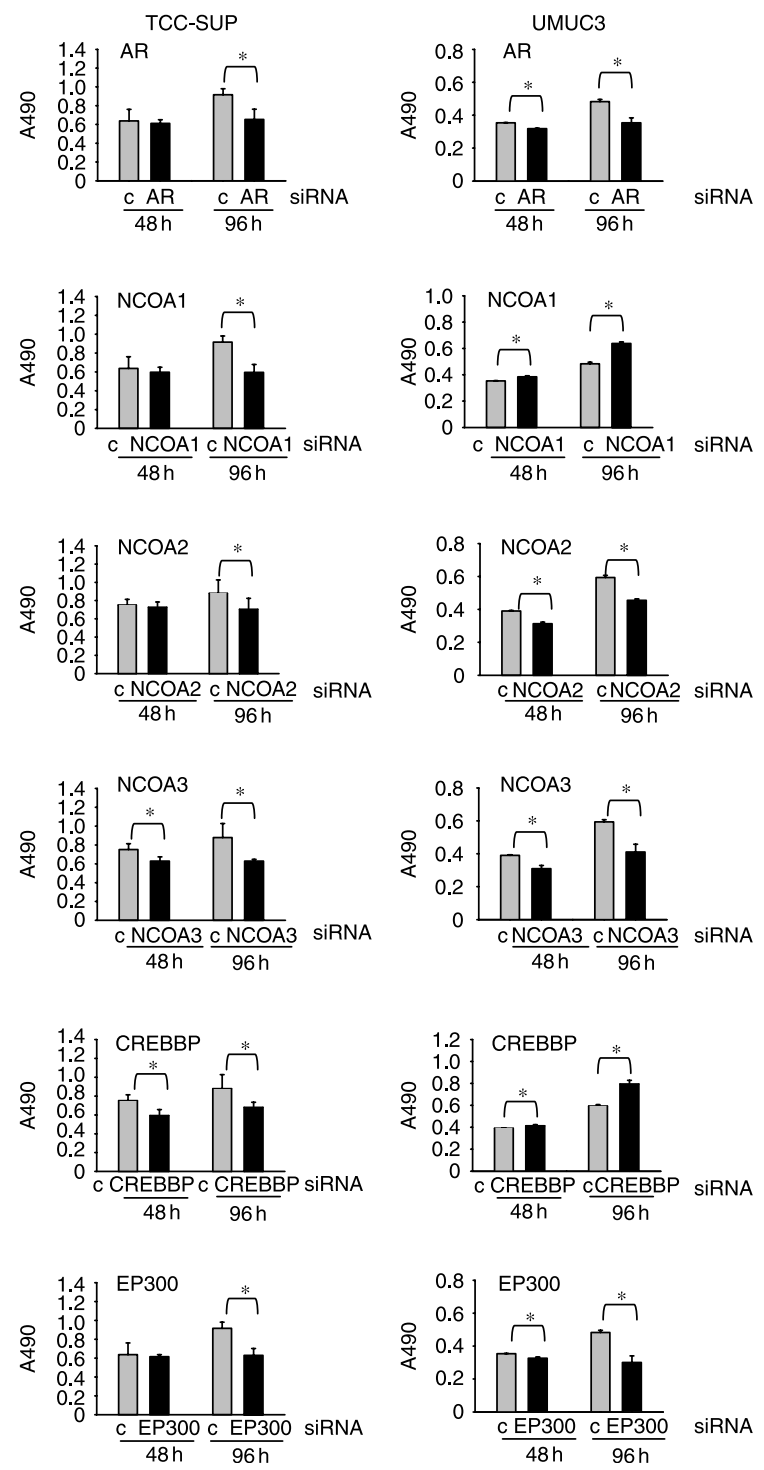

Figure 4 Importance of AR coactivator expression for UC cell viability. Cells were transfected with siRNA against the AR or AR coactivators (black columns) or with control siRNAs (gray columns). Twelve to $16 \mathrm{~h}$ after transfection, medium was changed. Forty-eight and $96 \mathrm{~h}$ later, cell viability was assessed by means of an MTS assay, reading absorbance at $490 \mathrm{~nm}$. Columns and vertical bars represent the mean \pm S.E.M. of five individual measurements. *Statistically significant difference compared with control, $P<0.05$.

under these conditions. As an additional control for the efficacy of our siRNA transfection, total protein extracts from cells transfected with siRNA against the AR or AR coactivators were analyzed by western blotting. As shown in Fig. 6, a significant decrease in the expression of the AR and the coactivators NCOA1, NCOA2, NCOA3, CREBBP, and EP300 was achieved in TCC-SUP as well as UMUC3 cells following transfection with specific siRNAs. This was true both at $48 \mathrm{~h}$ (data not shown) and (a) TCC-SUPP

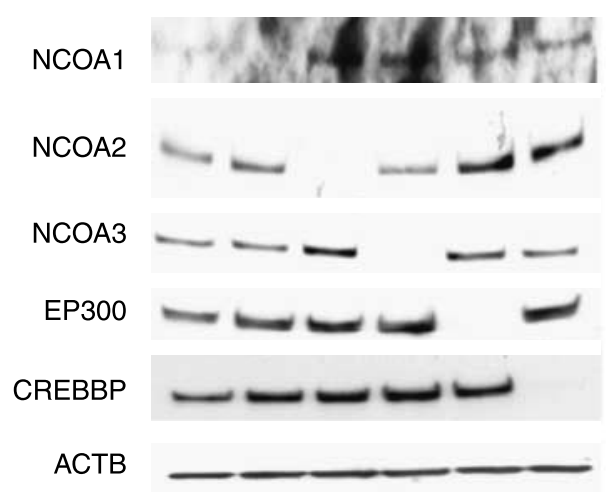

c NCOA1 NCOA2 NCOA3 EP300 CREBBP SIRNA

(b)

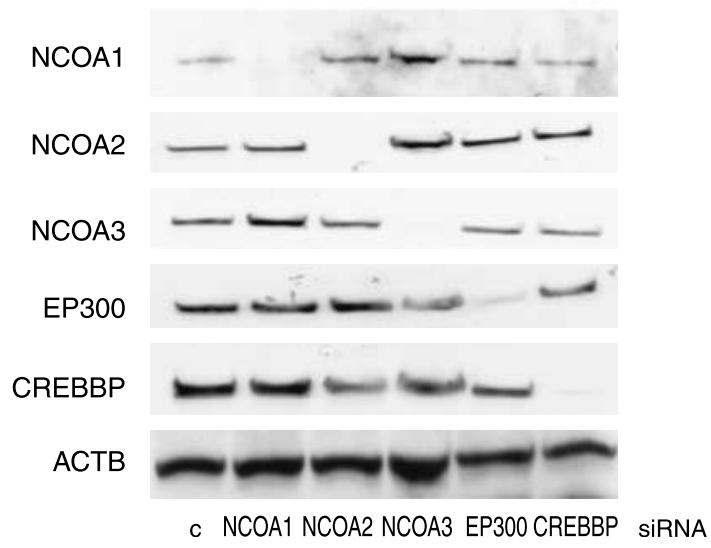

Figure 5 Compensatory effect of siRNA-mediated knockdown of AR coactivators on expression of functionally related coactivators in UC cells. TCC-SUP and UMUC3 cells were transfected with siRNA targeting coactivator expression or with control siRNA (c). On the next day, medium was replaced. Ninety-six hours later, cell lysates were prepared and subjected to immunoblot analysis using antibodies targeted against NCOA1, NCOA2, NCOA3, CREBBP, EP300, and $\beta$-actin.

$96 \mathrm{~h}$ (Fig. 6) post-transfection. Moreover, no marked differences in the efficiency of the siRNA-mediated knockouts could be observed between the cell lines.

Given the effects we observed from silencing expression of the AR and AR coactivators on the number of viable UC cells, we sought to determine whether this was due to changes in cell proliferation or apoptosis. Cell lysates obtained from TCC-SUP and UMUC3 cells transfected with siRNAs targeting the AR, AR coactivators, or control siRNAs were analyzed for expression of PARP cleavage, which is a widely recognized marker for cells undergoing apoptosis. As shown in Fig. 7, loss of expression of the AR or any of the coactivators examined did not generate a cleaved PARP fragment. These results 


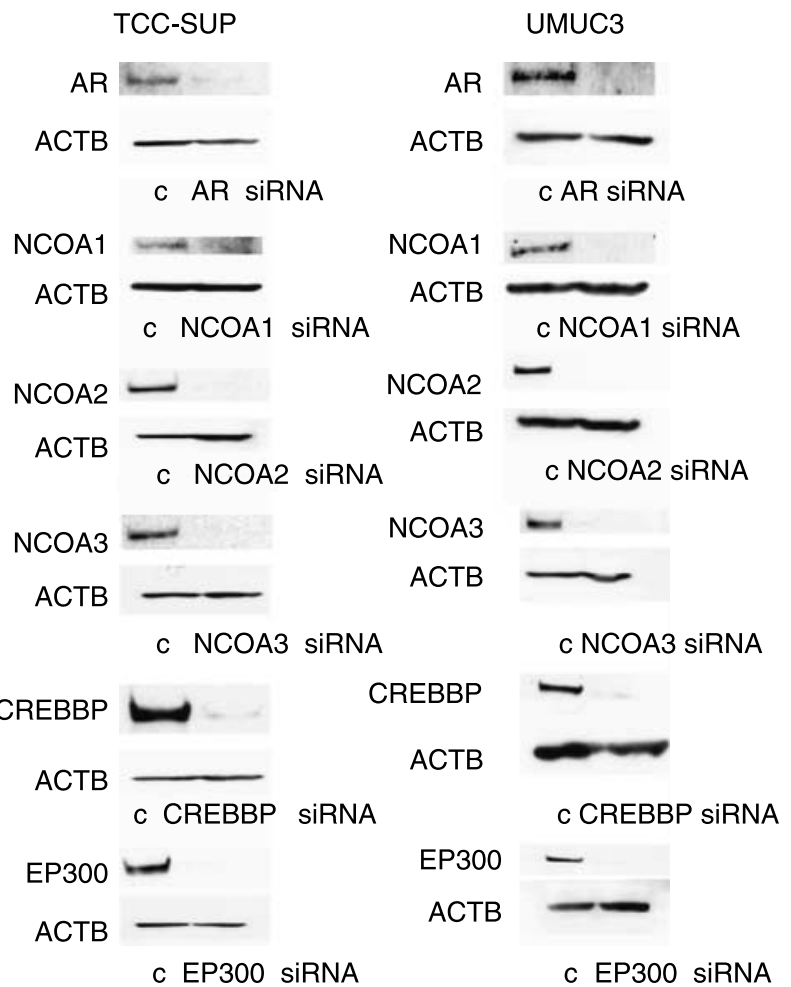

Figure 6 Effect of siRNA transfection on coactivator protein expression in UC cells. TCC-SUP and UMUC3 cells were transfected with siRNA targeting AR or AR coactivator expression or with control siRNA (c). On the next day, medium was replaced. Ninety-six hours later, cell lysates were prepared and blotted for the AR, NCOA1, NCOA2, NCOA3, CREBBP, EP300, and $\beta$-actin (ACTB).

were not due to technical limitations in detecting PARP cleavage, as the same amount of cellular protein obtained from cells induced to undergo apoptosis upon treatment with staurosporine yielded immunoreactive bands for an $89 \mathrm{kDa}$ PARP fragment (Fig. 7, right). Moreover, none of the siRNA-transfected cells demonstrated morphological features consistent with apoptosis (data not shown). Taken together, these data suggest that, as has been observed in prostate cancer cells (Agoulnik et al. 2006, Heemers et al. 2007), the changes in bladder cancer cell viability noted here with downregulation of AR or AR coactivator expression are not caused by an impact on apoptosis but result from alterations in cell proliferation.

\section{AR coactivators mediate the androgen responsiveness of UMUC3 cells}

We next evaluated the importance of the AR coactivators in mediating the androgen responsiveness of UC cells. We assessed the effect of silencing AR-associated coactivators as well as the AR on androgen-dependent
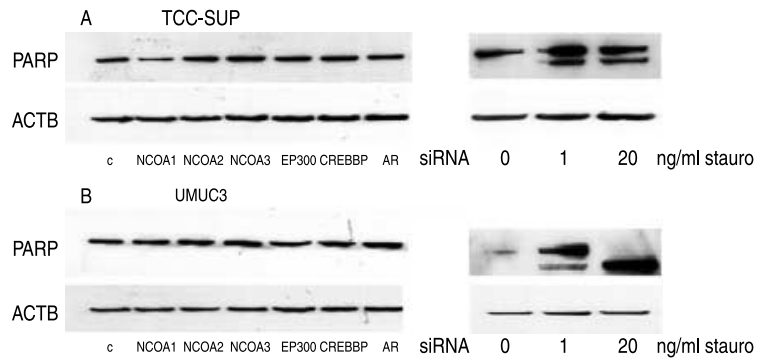

Figure 7 Loss of AR or AR coactivator expression in UC cells does not induce apoptosis. Cell lysates were obtained from (A) TCC-SUPP and (B) UMUC3 cells transfected with siRNAs targeting the AR, AR coactivators, or control siRNAs (c), as described. Western blotting for expression of the cleavage fragment of PARP was performed. Cell lysates obtained from TCC-SUP and UMUC3 cells treated with 0,1 , or $20 \mathrm{ng} / \mathrm{ml}$ staurosporine (Stauro) were similarly evaluated (right). To assess potential intersample loading differences, blots were stripped and reprobed with an antibody recognizing $\beta$-actin.

proliferation of UC cells. These experiments were performed with UMUC3 cells since the effects of androgen treatment were more pronounced in this cell line (Fig. 2). UMUC3 cells were transfected with siRNAs targeting the AR, AR coactivators, or non-targeting control siRNAs. One day after transfection, medium was changed, and the cells were treated with $1 \mathrm{nM}$ R1881 or ethanol. Cell viability was assessed with the MTS assay $96 \mathrm{~h}$ after androgen stimulation. Figure 8 confirms the androgen responsiveness of UMUC 3 cells (compare with Fig. 2), and shows similar changes in the number of viable cells upon loss of the AR and coactivators under androgen-deprived conditions (compare with Fig. 4). Importantly, we found that knockdown of AR expression or of any one of the five coactivators blunted the androgen responsiveness of these cells as measured by cell viability (Fig. 8), emphasizing the importance of these proteins in mediating the androgen-induced increase in the proliferation of UMUC3 cells.

\section{Androgen independence of AR coactivator expression in UC cell lines}

In prostate cancer, androgen regulation of AR-associated coregulator expression is emerging as an important mechanism to govern AR activity (Comuzzi et al. 2004, Agoulnik et al. 2006, Heemers et al. 2007, Heemers unpublished observations). Given the importance of AR coactivators for maintaining UC cell viability (Fig. 4) and for mediating androgen responsiveness of bladder cancer cells (Fig. 8), we investigated whether expression of the AR coactivators is androgen regulated in bladder cancer cells. Accordingly, we performed western blot analysis of whole cell lysates 

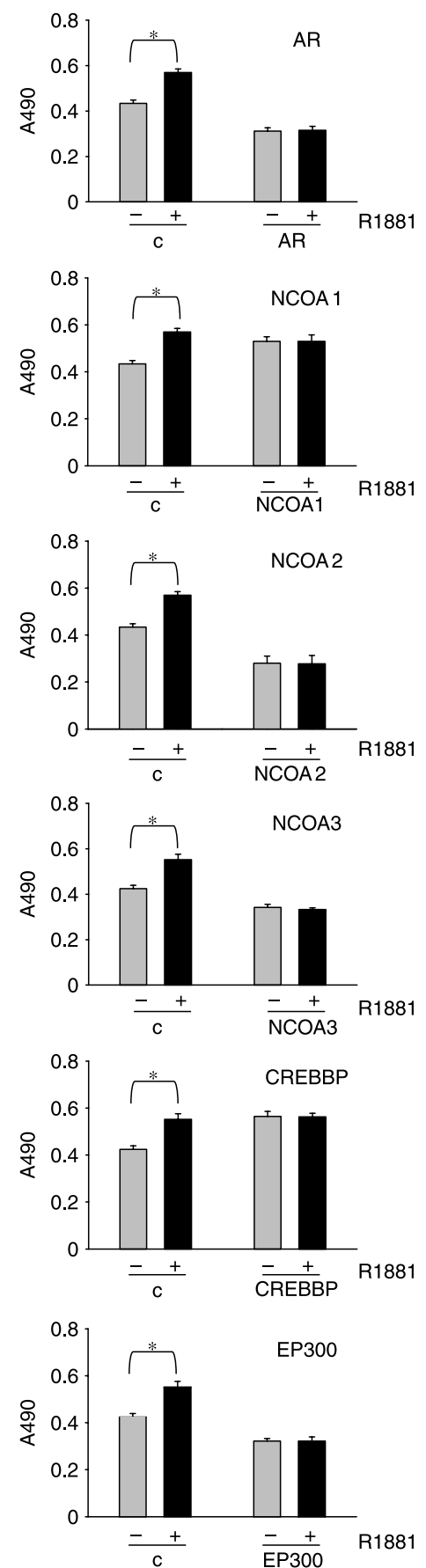

Figure 8 AR coactivators are important for androgen-dependent proliferation of UMUC3 cells. UMUC3 cells seeded in medium supplemented with CSS were transfected with siRNAs targeting the AR, AR coactivators, or non-targeting control siRNAs (c). One day after transfection, medium was changed and cells were treated with $1 \mathrm{nM} \mathrm{R} 1881$ (black columns) or ethanol vehicle (gray columns). Ninety-six hours later, cell viability was assessed by means of an MTS assay, reading absorbance at $490 \mathrm{~nm}$. Columns and vertical bars represent the mean \pm S.E.M. of five individual measurements. *Statistically significant difference compared with control, $P<0.05$. from cells cultured in the presence or absence of androgen for $48 \mathrm{~h}$ for each of the five coactivators. As can been seen in Fig. 9A, androgen stimulation did not impact the protein expression of any of the targets studied. Similarly, androgens did not modulate mRNA levels of any of these coregulators (Fig. 9B). Confirming these observations, loss of AR expression did not notably affect coactivator expression levels in either TCC-SUP or UMUC 3 cells (Fig. 9C). Taken together, these findings suggest marked differences in the mechanisms regulating $\mathrm{AR}$ action and coactivator expression between AR-positive malignancies such as bladder and prostate cancers.

\section{$A R$ and coactivator protein expression in human UC specimens}

In order to investigate the clinical relevance of AR coactivators in UC, we evaluated the expression of NCOA1, NCOA2, NCOA3, CREBBP, and EP300 in patient tissues. To this end, we performed immunohistochemistry on paraffin-embedded UC tumor sections from a cohort of patients who underwent radical cystectomy for UC of the bladder at Mayo Clinic. To evaluate the relative expression of the $\mathrm{AR}$ versus the expression of the coactivators in UC tumor tissue, staining was also performed for the AR.

We identified 60 patients from the Mayo Clinic Cystectomy Registry, 55 (91.7\%) for whom paraffinembedded tissue blocks were available for analysis. Twenty-four of these patients also had adjacent, nonneoplastic urothelium present on the tumor sections, which was evaluated for AR and coactivator expression as well. Median patient age was 68 years (range 39-86). Other clinicopathological features are summarized in Table 2. Overall, we found the expression of NCOA1, NCOA2, NCOA3, CREBBP, EP300, and AR in 50 out of $55(91 \%), 52$ out of $55(95 \%), 55$ out of $55(100 \%), 47$ out of $55(86 \%), 54$ out of $55(98 \%)$, and 24 out of $55(44 \%)$ of UC tumors respectively. Staining was typically nuclear for the AR and each of the coactivators examined and was uniform through the basal, middle, and luminal cell layers of urothelium (Fig. 10). None of the negative controls showed staining in either the tumor or adjacent bladder urothelium.

The levels of expression of the AR and each coactivator in matched tumor and adjacent non-tumor bladder tissue, assessed as the percentage of positive nuclear staining, are summarized in Table 3. Only NCOA1 demonstrated a significant difference in expression between UC and non-cancerous bladder tissue $(P=0.03)$. A decreased level of NCOA1 protein was detected within the tumors, while a trend toward 

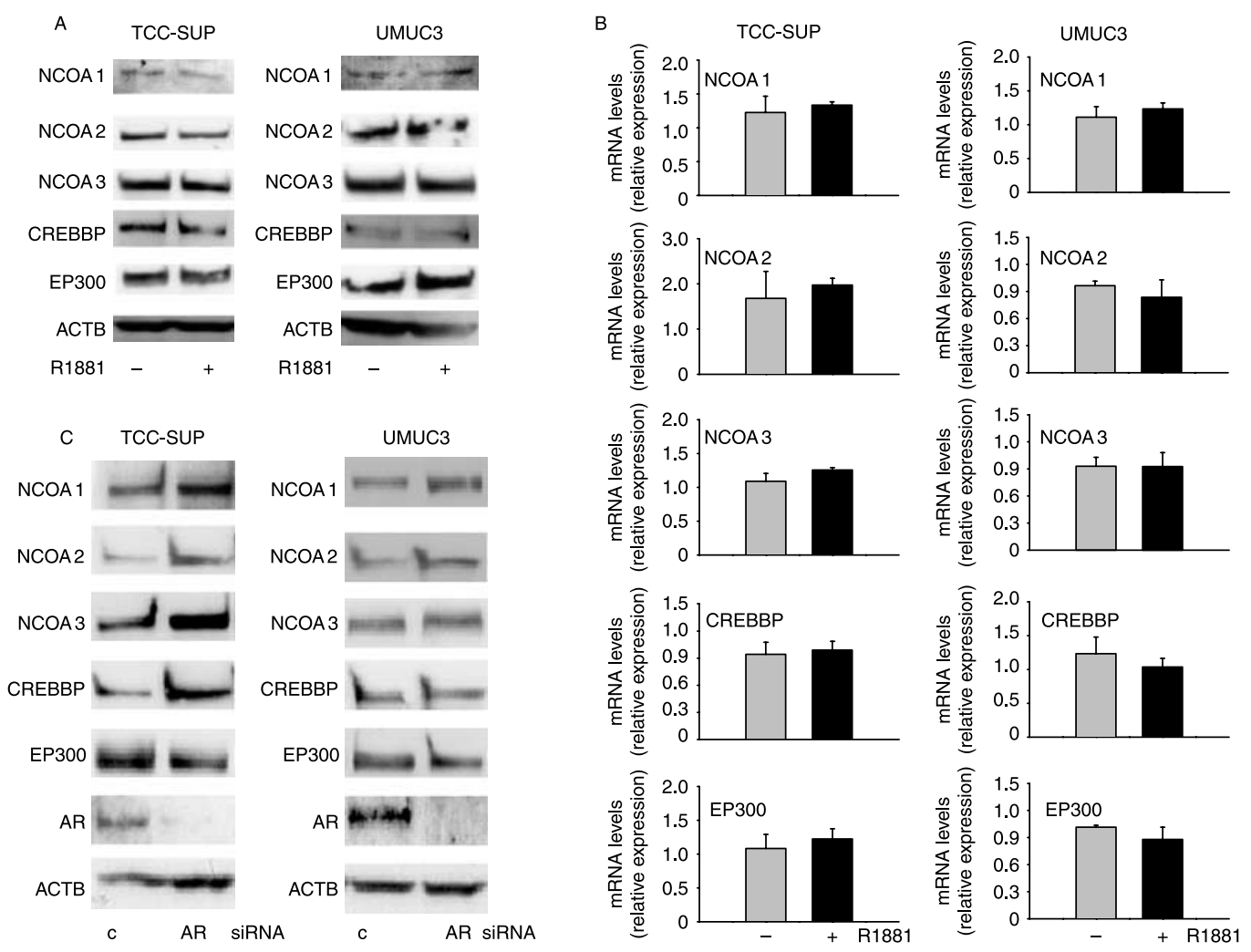

Figure 9 AR coactivator expression is not affected by androgen stimulation in UC cells. (A) TCC-SUP and UMUC cells were seeded in medium supplemented with CSS. Two days later, medium was changed and cells were treated with $1 \mathrm{nM}$ R1881 or ethanol vehicle for $48 \mathrm{~h}$. Total protein extracts were prepared, and equal amounts of protein were analyzed by western blotting using antibodies directed against NCOA1, NCOA2, NCOA3, CREBBP, and EP300. To assess potential intersample loading differences, blots were stripped and reprobed with an antibody recognizing $\beta$-actin. Blots representative of three separate experiments are shown.

(B) TCC-SUP and UMUC cells were seeded in medium supplemented with CSS. Two days later, medium was changed and cells were treated with $1 \mathrm{nM}$ R1881 (black bars) or ethanol vehicle (gray bars) for $48 \mathrm{~h}$. RNA was isolated and converted into cDNA. Realtime PCR was performed using primers specific for NCOA1, NCOA2, NCOA3, CREBBP, and EP300. mRNA levels were normalized with the values obtained from GAPDH expression. mRNA levels are expressed as relative expression values, taking the value obtained from one batch of cells treated with vehicle as 1. Columns, mean values obtained from biological triplicates; bars, S.E.M. (C) AR coactivator expression is independent of AR expression in UC cells. TCC-SUP and UMUC3 cells were transfected with siRNA targeting the AR or with control siRNA (c). On the next day, medium was replaced. Ninety-six hours later, cell lysates were prepared and blotted for the AR, NCOA1, NCOA2, NCOA3, CREBBP, EP300, and $\beta$-actin (ACTB).

increased expression of the AR in UC compared with non-tumor urothelium was also observed $(P=0.06)$. No significant difference in the frequency of coactivator expression was noted across different tumor stages (data not shown). However, AR expression tended to decrease with advanced pathological stage, as expression was noted in 13 out of $22(59 \%)$ pT $1 /$ CIS tumors versus in 8 out of $18(44 \%)$ pT2 lesions and in 3 out of $15(20 \%)$ pT3/4 cancers $(P=0.06)$, which is consistent with a previous report (Boorjian et al. 2004). In addition, the level of expression of each of the coactivators was independent of AR expression ( $P>0.05$ for all comparisons).

As there were only nine females and eight nonsmokers in the study cohort, formal statistical comparisons of coactivator expression with gender and smoking status were not performed. Nevertheless, consistent with our cell line data (the TCC-SUP cell line is derived from a female patient with UC, while the UMUC3 cell line is derived from a male patient), we did observe expression of the AR and each of the coactivators in the tissue specimens from women as well as men. In addition, since $85 \%$ of the tumors in our series were classified as grade $3 / 4$, and no grade 1 cancers were recorded, we did not assess the correlation of coactivator expression with tumor grade. Overall, we found high levels of AR coactivator expression in UC that did not correlate with tumor stage or AR expression. Moreover, only NCOA1 expression differed between tumor and non-tumor urothelium. Taken together, these results further suggest a dissimilarity in the regulation of coactivator expression between AR-positive malignancies such as bladder and prostate cancers. 
Table 2 Demographics of 55 patients with $\mathrm{UC}^{\mathrm{a}}$ of the bladder who had tissue blocks available for immunohistochemical analysis

\begin{tabular}{ll}
\hline Feature & \multicolumn{1}{c}{$\boldsymbol{N ( \% )}$} \\
\hline Gender & \\
Female & $9(16.4 \%)$ \\
Male & $46(83.6 \%)$ \\
Smoking status & \\
Never & $8(14.6 \%)$ \\
Past & $32(58.2 \%)$ \\
Current & $15(27.3 \%)$ \\
Tumor stage & \\
T1/CIS & \\
pT2 & $22(40 \%)$ \\
pT3/T4 & $18(32.7 \%)$ \\
Tumor grade & $15(27.3 \%)$ \\
1 & \\
2 & 0 \\
3 & $8(14.6 \%)$ \\
4 & $36(65.5 \%)$ \\
\hline
\end{tabular}

aUC, urothelial carcinoma.

${ }^{\mathrm{b}} \mathrm{CIS}$, carcinoma in situ.

\section{Discussion}

While previous epidemiologic and animal studies have suggested a role for sex steroids and the AR in UC, the regulation of $A R$ activity in bladder cancer has not been established. Efficient activation of the AR has been shown in other cell systems to depend on its association with coactivator proteins, which are recruited to the ligand-bound receptor and act as bridging factors to the transcriptional apparatus (Debes \& Tindall 2004, Heinlein \& Chang 2004, Lonard \& O'Malley 2005, Heemers \& Tindall 2007). Altered expression of these coactivators may result in changes in AR-regulated gene expression and in AR-mediated cell processes, including proliferation. Interestingly, coactivator proteins have been shown to mediate growth in hormone-responsive malignancies such as breast (Osborne et al. 2003) and prostate (Debes et al. 2003, Agoulnik et al. 2005, 2006, Zhou et al. 2005) cancers, and have also been found to be involved in tumors not typically considered to be hormone responsive, such as esophageal (Xu et al. 2007), gastric (Sakakura et al. 2000), and pancreatic (Henke et al. 2004) cancers.

Here, we present what is to our knowledge the first report of the expression and functional significance of AR coactivators in human UC cells. To date, $\sim 170$ coregulators have been described, which functionally and structurally interact with the AR (Heemers \& Tindall 2007). For our studies, we chose to explore the relevance of NCOA1, NCOA2, NCOA3, CREBBP, and EP300 in UC cells. These five coactivators are essential core components of the AR transcriptional complex (Heemers \& Tindall 2007). They interact directly with the AR, function as scaffold proteins that
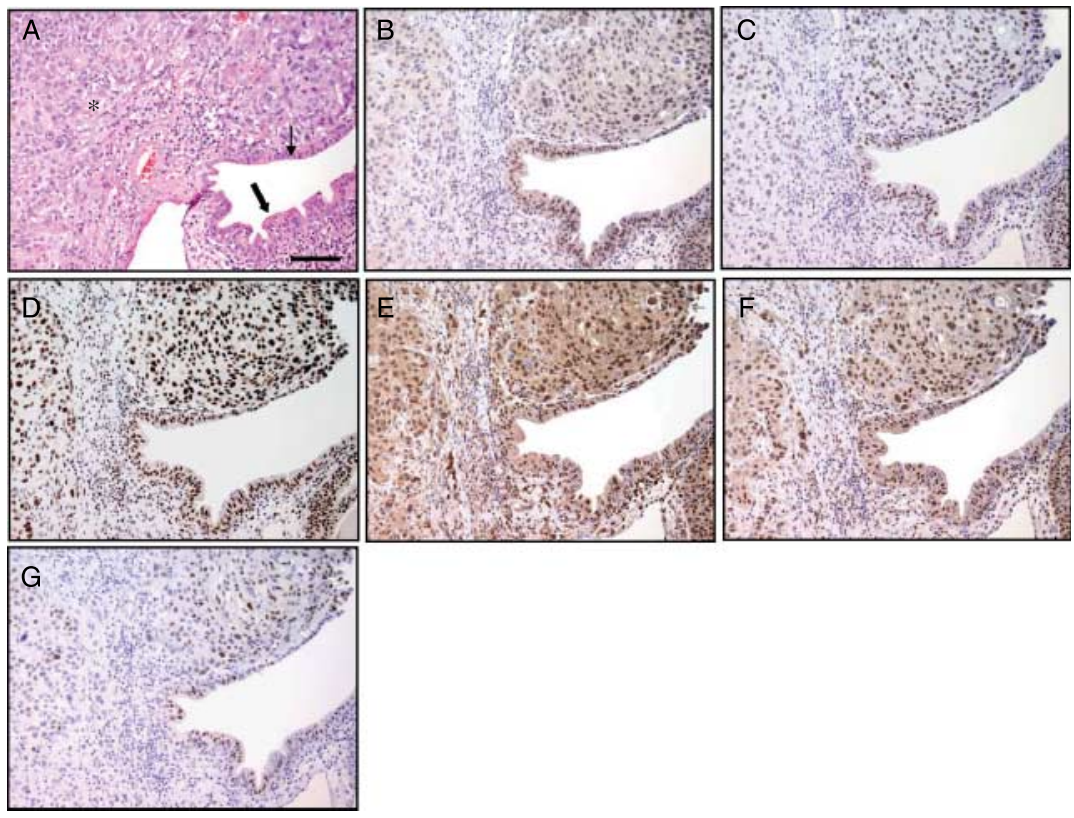

Figure 10 Expression of AR coactivators and the AR in human UC tumors. Serial tissue sections from a patient with stage pT3 UC of the bladder are shown. (A) H\&E section demonstrating areas of invasive tumor (asterisk), carcinoma in situ (thin arrow), and nontumor urothelium (thick arrow). Scale bar, $50 \mu \mathrm{m}$. Results of immunohistochemical staining for (B) NCOA1, (C) NCOA2, (D) NCOA3, (E) CREBBP, (F) EP300, and (G) AR. All images represent original magnification $\times 200$. 
Table 3 Expression of the androgen receptor (AR) and AR coactivators from patients with matched $U^{\mathrm{a}}$ and adjacent, nontumor bladder tissue

\begin{tabular}{|c|c|c|c|}
\hline $\begin{array}{l}\text { Target } \\
\text { molecule }^{\mathrm{b}}\end{array}$ & $\begin{array}{l}\%(+) \text { cells within } \\
\text { UC, mean (range) }\end{array}$ & $\begin{array}{c}\%(+) \text { cells in } \\
\text { non-tumor } \\
\text { urothelium, } \\
\text { mean (range) }\end{array}$ & $P$ value \\
\hline NCOA1 & $68.1 \%(0-100)$ & $80.5 \%(0-90)$ & 0.03 \\
\hline NCOA2 & $67.6 \%(0-100)$ & $62.2 \%(10-90)$ & 0.57 \\
\hline CREBBP & $61.8 \%(0-100)$ & $70.0 \%(0-100)$ & 0.51 \\
\hline EP300 & $78.4 \%(0-100)$ & $74.3 \%(20-90)$ & 0.96 \\
\hline AR & $15.8 \%(0-100)$ & $11.3 \%(0-50)$ & 0.06 \\
\hline
\end{tabular}

${ }^{\mathrm{a} U C}$, urothelial carcinoma.

${ }^{\mathrm{b}}$ As NCOA3 was nearly universally expressed at high levels in the tumor and non-tumor bladder tissue from all patients, no correlation with the presence or absence of UC could be determined for this coactivator.

attract additional coactivators to the $\mathrm{AR}$, and serve as a bridge between DNA-bound AR and the basal transcriptional machinery (Heemers \& Tindall 2007). Moreover, NCOA1, NCOA3, CREBBP, and EP300 possess histone acetyl transferase (HAT) activity, which induces acetylation of histone residues, resulting in a loosening of DNA-histone interactions and increased accessibility of the nucleosomal DNA to the transcriptional machinery (Fu et al. 2000, Xu \& Li 2003, Kalkhoven 2004). In fact, potentiation of ligandinduced AR transactivation by these coactivators has been shown to rely on the presence of a functional HAT domain (Aarnisalo et al. 1998, Fu et al. 2000, 2003). Additionally, in the case of EP300, its HAT moiety has been shown to acetylate the AR as well (Fu et al. 2000). Point mutations in these acetylation sites selectively prevent androgen induction of target genes and hamper coactivation of the AR by coregulators such as NCOA1 and EP300 (Fu et al. 2003). Importantly, in prostate cancer, where the $\mathrm{AR}$ is emerging as a critical determinant of cell proliferation, increased expression of NCOA1, NCOA2, NCOA3, CREBBP, and EP300 has been observed during disease progression (Gregory et al. 2001, Debes et al. 2003, Comuzzi et al. 2004, Agoulnik et al. 2005, 2006, Zhou et al. 2005). Deregulated expression of these coactivators generally correlates with poor prognosis in patients (Gregory et al. 2001, Debes et al. 2003, Comuzzi et al. 2004, Agoulnik et al. 2005, 2006, Zhou et al. 2005), and has been attributed at least in part to androgen control over coactivator expression (Comuzzi et al. 2004, Agoulnik et al. 2006, Heemers et al. 2007, HV Heemers unpublished observations).

We found that the AR-positive UC cell lines TCCSUP and UMUC3 expressed NCOA1, NCOA2, NCOA3, CREBBP, and EP300. Moreover, each of these five AR coactivators mediated the cellular response to androgens and independently impacted cell viability. In TCC-SUP cells, knockdown of any one of the coactivators resulted in a significant decrease in cell viability. In UMUC 3 cells, on the other hand, a decrease in the expression of NCOA2, NCOA3, or EP300 diminished cell viability, while knockdown of NCOA1 or CREBBP expression was associated with an increase in cell viability. Interestingly, a compensatory increase in the expression of NCOA2 and NCOA3 has been observed in prostate cancer cells upon siRNA-mediated suppression of NCOA1 (Wang et al. 2005). It is unlikely that a similar mechanism can account for the increase in cell viability observed in UMUC3 cells upon loss of NCOA1 or CREBBP expression, as we did not observe differences in the expression pattern of any of the five coactivators studied here between TCC-SUP and UMUC3 cells under these conditions. However, the impact of the loss of NCOA1 or CREBBP on expression of additional coregulators or proteins relevant to cell proliferation was not assessed. Most likely, our results reflect the diverse, overlapping cellular functions of nuclear receptor coactivators.

Noteworthy, contrary to observations in AR-positive prostate cancer cells, where expression of NCOA1 (Heemers unpublished observation), NCOA2 (Agoulnik et al. 2006), NCOA3 (Heemers unpublished observation), CREBBP (Comuzzi et al. 2004), and EP300 (Heemers et al. 2007) have been shown to be subject to androgen control, no effects of androgens on the expression level of any of these coactivators could be discerned in TCC-SUP or UMUC3 cells. These results are further supported by AR-knockdown experiments, in which siRNA-mediated suppression of AR expression did not notably affect AR coactivator expression. These observations point to differential regulation of AR-associated coactivators, and, consequently, of AR activity, in AR-positive bladder and prostate cancer cells. At the same time, moreover, we found that androgen stimulation decreased AR expression in UMUC3 cells. Again, this effect differs from the noted impact of androgens on AR expression in prostate cancer (Krongrad et al. 1991), and may reflect tissue-specific regulation of AR stability or expression. For example, given that the decrease in AR expression with androgen exposure was noted at both the mRNA and protein levels, the possibility exists that androgen treatment may induce the recruitment of repressor proteins to the androgen-response element of the AR promoter in UMUC3 cells, thereby inhibiting its transcriptional complex. 
In the tissue specimens from patients with bladder cancer, we detected high levels of coactivator expression in both the malignant and non-tumor bladder specimens from both male and female patients. Coactivator expression patterns did not correlate with the expression of the AR, suggesting that these coactivators are constitutively expressed by human urothelium and may mediate functions integral to cell survival, which may or may not be androgen regulated. Indeed, coactivators have been found to be involved in a number of biological processes, including cell proliferation, cell migration, and cell differentiation (Liao et al. 2002), and have been shown to interact with an array of other nuclear receptors (Takeshita et al. 1997), as well as with non-steroid hormone transcription factors such as activator protein-1 (Lee et al. 1998) and nuclear factor- $\kappa \mathrm{B}$ (Werbajh et al. 2000). These results, as well as the increasing evidence of a role for various hormone receptors in UC, including the estrogen receptor (Shen et al. 2006, Sonpavde et al. 2007), with which these coactivators may interact, support the AR- and androgen-independent importance of coactivators in bladder cancer cells.

Although other studies have demonstrated expression of the AR in human UC specimens (Zhuang et al. 1997, Boorjian et al. 2004), the expression of AR coactivators in bladder cancer has received limited attention. Luo et al. (2008). recently reported NCOA3 overexpression in UC tumors compared with nontumor urothelium in a series of 131 patients with UC from China, and found that overexpression was an independent predictor of survival. However, unlike our results, minimal expression of NCOA3 was noted in non-tumor urothelium, and no AR expression was reported in any of the bladder tissue studied (Luo et al. 2008). Our results regarding AR expression are consistent with the findings from a previous study, which noted decreased AR protein expression with increasing tumor stage (Boorjian et al. 2004). Such discrepancies between studies may be the result of different staining conditions, criteria for overexpression, and/or patient populations. Moreover, as the primary goal of the immunohistochemical analysis here was to establish the distribution of expression of AR coactivators in UC, the sample size chosen for study was not sufficiently robust for a meaningful assessment of the prognostic significance of coactivator expression. Additional studies involving larger numbers of patients are therefore needed to determine the association of $\mathrm{AR}$ and $\mathrm{AR}$ coactivator expression with survival for patients with UC of the bladder.

The decrease in AR expression with increasing bladder tumor stage noted here and previously
(Boorjian et al. 2004) is different than the expression in advanced prostate cancer, where stable or even increased AR expression has been reported (Debes \& Tindall 2004, Mohler 2008). Whether the AR retains a functional significance across various stages of bladder cancer, as in prostate cancer (Debes \& Tindall 2004, Mohler 2008), requires further investigation. At the same time, the significant downregulation of NCOA1 expression in bladder tumor tissue versus non-tumor urothelium noted here, which occurred independent of tumor stage, together with our finding that knockout of NCOA1 expression in UMUC3 cells significantly increases cell proliferation, suggests a possible role for NCOA1 downregulation early in the malignant transformation of urothelial cells. Moreover, our observations that the level of coactivator expression does not correlate with AR expression in human tissue, and that androgens do not affect the expression of any of these coactivators, suggest alternative mechanisms of coactivator regulation in bladder cancer versus in other AR-positive malignancies such as prostate cancer. Post-translational modifications such as acetylation and phosphorylation represent additional potential mechanisms by which coactivator activity may be regulated. In fact, previous studies have documented phosphorylation sites in coactivators and have demonstrated that growth factor signaling through the ERBB2/MAPK pathways impacts coactivator activity and interaction with steroid receptors (Yeh et al. 1999, Font de Mora \& Brown 2000, Rowan et al. 2000, Bouras et al. 2001, Ueda et al. 2002, Osborne et al. 2003). Similarly, the neuropeptide bombesin has been found to mediate EP300 HAT activity through the NCOA kinase and PRKCD kinase signaling pathways in prostate cancer cells (Gong et al. 2006).

In summary, our data provide initial insights into the role of AR coactivators in bladder cancer cells. As noted previously, $\sim 170$ AR coregulators have been identified to date (Heemers \& Tindall 2007). Thus, while we focused the present analysis on five of these which have been considered core coactivators based on their function in the AR transcriptional complex (Heemers \& Tindall 2007), the possibility remains that additional coactivators are important to AR function and to intracellular processes in bladder cancer as well. Characterizing the molecular machinery responsible for AR regulation and activity in UC may lead to novel avenues for therapeutic intervention. Indeed, despite improvements in surgical technique and perioperative care, the survival rates of patients undergoing cystectomy for organ-confined bladder cancer have not significantly improved in 
recent years (Herr et al. 2007). Thus, even patients with what is considered relatively favorable pathology may benefit from treatment in addition to surgery. Whether the coactivators represent important targets for such adjuvant treatment strategies awaits the results of further investigations.

\section{Declaration of interest}

The authors declare that there is no conflict of interest that would prejudice the impartiality of this scientific work.

\section{Funding}

This work was supported by grants from the National Institutes of Health (CA121277, CA91956, and CA15083 to D J T), the T J Martell Foundation, and a grant from the Mayo Clinic Small Grants Program (to D J T).

\section{References}

Aarnisalo P, Palvimo JJ \& Jänne OA 1998 CREB-binding protein in androgen receptor-mediated signaling. PNAS $952122-2127$.

Agoulnik IU, Vaid A, Bingman WE III, Erdeme H, Frolov A, Smith CL, Ayala G, Ittmann MM \& Weigel NL 2005 Role of SRC-1 in the promotion of prostate cancer cell growth and tumor progression. Cancer Research 65 7959-7967.

Agoulnik IU, Vaid A, Nakka M, Alvarado M, Bingman WE III, Erdem H, Frolov A, Smith CL, Ayala GE, Ittmann MM et al. 2006 Androgens modulate expression of transcription intermediary factor 2 , an androgen receptor coactivator whose expression level correlates with early biochemical recurrence in prostate cancer. Cancer Research 66 10594-10602.

Boorjian S, Ugras S, Mongan NP, Gudas LJ, You X, Tickoo SK \& Scherr DS 2004 Androgen receptor expression is inversely correlated with pathologic tumor stage in bladder cancer. Urology 64 383-388.

Boorman GA 1977 Animal model of human disease; carcinoma of the ureter and urinary bladder. American Journal of Pathology 88 251-254.

Bouras T, Southey MC \& Venter DJ 2001 Overexpression of the steroid receptor coactivator AIB1 in breast cancer correlates with the absence of estrogen and progesterone receptors and positivity for p53 and HER2/neu. Cancer Research 61 903-907.

Chen F, Langenstroer P, Zhang G, Iwamoto Y \& See WA 2003 Androgen dependent regulation of bacillus Calmette-Guerin induced interleukin-6 expression in human transitional carcinoma cell lines. Journal of Urology 170 2009-2013.

Comuzzi B, Nemes C, Schmidt S, Jasarevic Z, Lodde M, Pycha A, Bartsch G, Offner F, Culig Z \& Hobisch A 2004 The androgen receptor co-activator $\mathrm{CBP}$ is up-regulated following androgen withdrawl and is highly expressed in advanced prostate cancer. Journal of Pathology 204 159-166.
Debes JD \& Tindall DJ 2004 Mechanisms of androgenrefractory prostate cancer. New England Journal of Medicine 351 1488-1490.

Debes JD, Sebo TJ, Lohse CM, Murphy LM, Haugen DAL \& Tindall DJ 2003 p300 in prostate cancer proliferation and progression. Cancer Research 63 7638-7640.

Debes JD, Comuzzi B, Schmidt LJ, Dehm SM, Culig Z \& Tindall DJ 2005 p300 regulates androgen receptorindependent expression of prostate-specific antigen in prostate cancer cells treated chronically with interleukin-6. Cancer Research 65 5965-5973.

Dehm SM \& Tindall DJ 2006 Molecular regulation of androgen action in prostate cancer. Journal of Cellular Biochemistry 99 333-344.

Font de Mora J \& Brown M 2000 AIB1 is a conduit for kinase-mediated growth factor signaling to the estrogen receptor. Molecular and Cellular Biology 20 5041-5047.

Fu M, Wang C, Reutens AT, Wang J, Angeletti RH, SiconolfiBaez L, Ogryzko V, Avantaggiati ML \& Pestell RG 2000 p300 and p300/cAMP-response element-binding proteinassociated factor acetylate the androgen receptor at sites governing hormone-dependent transactivation. Journal of Biological Chemistry 275 20853-20860.

Fu M, Rao M, Wang C, Sakamaki T, Wang J, Di Vizio D, Zhang X, Albanese C, Balk S, Chang C et al. 2003 Acetylation of androgen receptor enhances coactivator binding and promotes prostate cancer cell growth. Molecular and Cellular Biology 23 8563-8575.

Gong J, Zhu J, Goodman OB Jr, Pestell RG, Schlegel PN, Nanus DM \& Shen R 2006 Activation of p300 histone acetyltransferase activity and acetylation of the androgen receptor by bombesin in prostate cancer cells. Oncogene 25 2011-2021.

Gregory CW, He B, Johnson RT, Ford OH, Mohler JL, French FS \& Wilson EM 2001 A mechanism for androgen receptormediated prostate cancer recurrence after androgen deprivation therapy. Cancer Research 61 4315-4319.

Hartge P, Harvey EB, Linehan WM, Silverman DT, Sullivan JW, Hoover RN \& Fraumeni JF Jr 1990 Unexplained excess risk of bladder cancer in men. Journal of the National Cancer Institute 82 1636-1640.

Heemers HV \& Tindall DJ 2005 Androgen receptor coregulatory proteins as potential therapeutic targets in the treatment of prostate cancer. Current Cancer Therapy Reviews 1 175-186.

Heemers HV \& Tindall DJ 2007 Androgen receptor (AR) coregulators: a diversity of functions converging on and regulating the AR transcriptional complex. Endocrine Reviews 28 778-808.

Heemers HV, Sebo TJ, Debes JD, Regan KM, Raclaw KA, Murphy LM, Hobisch A, Culig Z \& Tindall DJ 2007 Androgen deprivation increases p300 expression in prostate cancer cells. Cancer Research 67 3422-3430.

Heinlein CA \& Chang C 2004 Androgen receptor in prostate cancer. Endocrine Reviews 25 276-308. 
Henke RT, Haddad BR, Kim SE, Rone JD, Mani A, Jessup JM, Wellstein A, Maitra A \& Riegel AT 2004 Overexpression of the nuclear receptor coactivator AIB1 (SRC-3) during progression of pancreatic adenocarcinoma. Clinical Cancer Research 10 6134-6142.

Herr HW, Dotan Z, Donat SM \& Bajorin DF 2007 Defining optimal therapy for muscle invasive bladder cancer. Journal of Urology 177 437-443.

Imada S, Akaza H, Ami Y, Koiso K, Ideyama Y \& Takenaka T 1997 Promoting effects and mechanisms of action of androgen in bladder carcinogenesis in male rats. European Urology 31 360-364.

Jemal A, Siegel R, Ward E, Murray T, Xu J \& Thun MJ 2007 Cancer statistics, 2007. CA: A Cancer Journal for Clinicians 57 43-66.

Kalkhoven E 2004 CBP and p300: HATs for different occasions. Biochemical Pharmacology 68 1145-1155.

Krongrad A, Wilson CM, Wilson JD, Allman DR \& McPhaul MJ 1991 Androgen increases androgen receptor protein while decreasing receptor $\mathrm{mRNA}$ in LNCaP cells. Molecular and Cellular Endocrinology 76 79-88.

Lee SK, Kim HJ, Na SY, Kim TS, Choi HS, Im SY \& Lee JW 1998 Steroid receptor coactivator-1 coactivates activating protein-1-mediated transactivations through interaction with the c-Jun and c-Fos subunits. Journal of Biological Chemistry 273 16651-16654.

Liao L, Kuang SQ, Yuan Y, Gonzalez SM, O’Malley BW \& $\mathrm{Xu} \mathrm{J} 2002$ Molecular structure and biological function on the cancer-amplified nuclear receptor cofactor SRC3/AIB1. Journal of Steroid Biochemistry and Molecular Biology 83 3-14.

Liu CH, Huang JD, Huang SW, Hour TC, Huang YK, Hsueh YM, Chiou HY, Lee TC, Jan KY, Chen CJ et al. 2007 Androgen receptor gene polymorphism may affect the risk of urothelial carcinoma. Journal of Biomedical Science 15 261-269.

Lonard DM \& O'Malley BW 2005 Expanding functional diversity of the coactivators. Trends in Biochemical Sciences 30 126-132.

Luo JH, Xie D, Liu MZ, Chen W, Liu YD, Wu GQ, Kung HF, Zeng YX \& Guan XY 2008 Protein expression and amplification of AIB1 in human urothelial carcinoma of the bladder and overexpression of AIB is a new independent prognostic marker of patient survival. International Journal of Cancer 122 2554-2561.

Miyamoto H, Yang Z, Chen YT, Ishiguro H, Uemura H, Kubota Y, Nagashima Y, Chang YJ, Hu YC, Tsai MY et al. 2007 Promotion of bladder cancer development and progression by androgen receptor signals. Journal of the National Cancer Institute 99 558-568.

Mohler JL 2008 Castration-recurrent prostate cancer is not androgen-independent. Advances in Experimental Medicine and Biology 617 223-234.

Moore KL \& Persaud TVN 1993 The urogenital system. In The Developing Human, pp 276-289. Eds KL Moore \& TVN Persaud., 5 Philadelphia: WB Saunders.
Okajima E, Hiramatsu T, Iriya K, Ijuin M \& Matsushima S 1975 Effects of sex hormones on development of urinary bladder tumours in rats induced by $N$-butyl- $N$-(4-hydroxybutyl) nitrosamine. Urological Research 3 73-79.

Osborne CK, Bardou V, Hopp TA, Chamness GC, Hilsenbeck SG, Fuqua SAW, Wong J, Allred DC, Clark GM \& Schiff R 2003 Role of the estrogen receptor coactivator AIB1 (SRC-3) and HER-2/neu in tamoxifen resistance in breast cancer. Journal of the National Cancer Institute 95 353-361.

Rowan BG, Weigel NL \& O’Malley BO 2000 Phosphorylation of steroid receptor coactivator-1: identification of the phosphorylation sites and phosphorylation through mitogen-activated protein kinase pathway. Journal of Biological Chemistry 275 4475-4483.

Sakakura C, Hagiwara A, Yasuoka R, Fujita Y, Nakanishi M, Masuda K, Kimura A, Nakamura Y, Inazawa J, Abe T et al. 2000 Amplification and over-expression of the AIB1 nuclear receptor co-activator gene in primary gastric cancers. International Journal of Cancer 89 217-223.

Shen SS, Smith CL, Hsieh JT, Yu J, Kim IY, Jian W, Sonpavde G, Ayala GE, Younes M \& Lerner SP 2006 Expression of estrogen receptors- $\alpha$ and $-\beta$ in bladder cancer cell lines and human bladder tumor tissue. Cancer 106 2610-2616.

Sonpavde G, Okuno N, Weiss H, Yu J, Shen SS, Younes M, Jian W, Lerner SP \& Smith CL 2007 Efficacy of selective estrogen receptor modulators in nude mice bearing human transitional cell carcinoma. Urology 69 1221-1226.

Takeshita A, Cardona GR, Kiobuchi N, Suen CH \& Chin WW 1997 TRAM-1, a novel 160-kDa thyroid hormone receptor activator molecule, exhibits distinct properties from steroid receptor coactivator-1. Journal of Biological Chemistry 272 27629-27634.

Teng J, Wang ZY, Jarrad DF \& Bjorling DE 2008 Roles of estrogen receptor $\alpha$ and $\beta$ in modulating urothelial cell proliferation. Endocrine-Related Cancer 15 351-364.

Ueda T, Mawji NR, Bruchovsky N \& Sadar MD 2002 Ligand-independent activation of the androgen receptor by interleukin- 6 and the role of steroid receptor coactivator-1 in prostate cancer cells. Journal of Biological Chemistry 277 38087-38094.

Veldscholte J, Berrevoets CA \& Mulder E 1994 Studies on the human prostatic cancer cell line LNCaP. Journal of Steroid Biochemistry and Molecular Biology 49 341-346.

Wang Q, Carroll JS \& Brown M 2005 Spatial and temporal recruitment of androgen receptor and its coactivators involves chromosomal looping and polymerase tracking. Molecular Cell 19 631-642.

Werbajh S, Nojek I, Lanz R \& Costas MA 2000 RAC-3 is a NF- $\kappa \mathrm{B}$ coactivator. FEBS Letters 485 195-199. 
Xu J \& Li Q 2003 Review of the in vivo functions of the p160 steroid receptor coactivator family. Molecular Endocrinology 17 1681-1692.

Xu FP, Xie D, Wen JM, Wu HX, Liu YD, Bi J, Lv ZL, Zeng YX \& Guan XY 2007 SRC-3/AIB1 protein and gene amplification levels in human esophageal squamous cell carcinomas. Cancer Letters $\mathbf{2 4 5}$ 69-74.

Yeh S, Lin HK, Kang HY, Thin TH, Lin MF \& Chang C 1999 From HER2/neu signal cascade to androgen receptor and its coactivators: a novel pathway for induction of androgen target genes through MAP kinase in prostate cancer cells. PNAS 96 5458-5463.

Zhou HJ, Yan J, Luo W, Ayala G, Lin SH, Erdem H, Ittmann M, Tsai SY \& Tsai MJ 2005 SRC-3 is required for prostate cancer cell proliferation and survival. Cancer Research 65 7976-7983.

Zhuang YH, Blauer M, Tammela T \& Tuohimaa P 1997 Immunodetection of androgen receptor in human urinary bladder cancer. Histopathology 30 556-562. 